\title{
Optimization of a Tunable Photonic Crystal Filter for Coarse Wavelength Division Multiplexing
}

\author{
F. Brik ${ }^{1, *}$, A. Labbani2,† \\ ${ }^{1}$ Badji Mokhtar Annaba University, Laboratory of LERICA Communication \& Instrumentation, Annaba, Algeria \\ 2 Mentouri Brother Constantine1, Laboratory of Hyper Frequency and Semiconductors, Constantine, Algeria
}

(Received 05 June 2020; revised manuscript received 21 December 2020; published online 25 December 2020)

The design of a tunable Add Drop Filter (ADF) based on photonic crystal is proposed in this work, which is revealed as one of the most promising technologies for Wavelength Division Multiplexing (WDM) networks. By using the Fullwave tool of the Rsoft CAD program, we simulated a photonic crystal ring resonator model similar to the basic one. The analytical methods Plane Wave Expansion (PWE) and 2D Finite Difference Time Domain (FDTD) were used to perform simulations and to test the optical properties of the system. Simulation results made it possible to implement a model of a highly selective tunable photonic crystal ring resonator with an extraction rate of approximately $98 \%$ and an area of about $100 \mu \mathrm{m}^{2}$, which is compatible with the intended integrated optics.

Keywords: ADF, Photonic crystal, Tunability, FDTD.

DOI: 10.21272/jnep.12(6).06035

PACS numbers: 42.70.Qs, 42.79.Gn

\section{INTRODUCTION}

Wavelength filtering is one of the most important functionalities in optical telecommunication systems.

Existing optical filter technologies include: FabryPerot [1-3], Phasar [4-6], Bragg grating [7, 8], and ring resonator filters [9-11]. However, it is important to approach photonic crystals, as they provide an opening for compact integration of optics $[12,13]$.

Photonic crystal ring resonators (PCRRs) have proven to be one of the most promising technologies for wavelength division multiplexing (WDM) networks.

Thus far, several topologies for the channel drop filter have been proposed, such as the use of resonators. And many works related to PCRRs have been published. For the first time, Kim et al. [14] used a PCRR for designing a waveguide ring laser cavity. Recently, Mahmoud et al. [15] introduced a new optical filter based on a PCRR and used an X-shaped structure as its resonant ring. Other authors have mentioned the effect of different parameters of PCRR filtering [16]. It is noted that in the above works, different structures and materials have been used depending on the desired application.

A distinctive feature of our model is that the resonance wavelength of a ring resonator is tunable while keeping dimensions compatible with the integrated optics. Our team focused on modeling a ring resonator filter based on photonic crystal through the Rsoft Photonique CAD software's Fullwave module, which is being implemented in the FDTD process. The model is based on a square lattice of a $2 \mathrm{D}$ photonic crystal structure composed of dielectric rods.

In the following sections, the basic theory of this resonator and the tools used in the simulation are presented. Then the simulation results obtained are demonstrated.

\footnotetext{
* fatima.brik@univ-annaba.dz

$\dagger$ labbani.amel@umc.edu.dz
}

\section{THEORY OF A RING RESONATOR AND ANALYSIS METHOD}

\subsection{Theory of a Ring Resonator}

The classical optical ring resonator consists of a structure with four ports distributed on two symmetrical planar waveguides enclosing a ring. The resonator process is essentially based on three optical phenomena, namely, total internal reflection, optical coupling, and constructive interference.

Part of the incident light in the input port (total internal reflection) is coupled with the ring (this is the optical coupling), depending on three parameters: the distance between the waveguide and the ring, the coupling zone, and the difference index between the waveguide and the ring.

Then, constructional interference is established in the resonant ring. That light is then decoupled towards the drop port.

\subsection{Analysis Method}

The FDTD is one of the most widely used numerical methods for computing the solution of electromagnetic problems, including photonic structures. It gives us an easy way to distinguish the Maxwell equations without requiring complex mathematical formulation. Furthermore, the FDTD can be used for the inhomogeneous structural parts in 2D or 3D forms and does not need any symmetry in the structure being modeled [17].

The FDTD approach is used here to discretize Maxwell equations with a time step $\Delta t$, spatial measures like $\Delta x$ and $\Delta y$ which are the distances between two adjacent grid points, respectively, along the $x$ and $y$ directions in the $x y$-coordinate system [18].

The computational domain has a rectangular shape in the $x y$ plane. The spatial discretization in the FDTD simulation is chosen to be $\Delta x=\Delta y=0.01 \mu \mathrm{m}$. A modulat- 
ed Gaussian pulse is used to provide a wideband excitation at any desired position within the photonic crystal computing domain. Given that data storage in a computer is constrained by the size of its memory, an open region issue should not be addressed directly. To mitigate this issue, the perfectly matched layer (PML) technique $[19,20]$ is commonly used in FDTD simulations.

\section{DESIGN OF AN ADF FILTER BASED ON PHOTONIC CRYSTAL}

The model drawn up in this work is inspired by the basic model. We used 2D square lattice photonic crystal composed of dielectric rods, the number of which in the $x$ and $z$ directions is $20 \times 19$, respectively.

The lattice constant is $540 \mathrm{~nm}$ and the radius of the pores is $0.185 a$. The rods have a dielectric constant $\mathcal{E}_{r}=12.04$

A typical ring resonator that is obtained by removing a column ring shape from a square lattice of dielectric rods in the air context is shown in Fig. 1a. Remember that the 3D structure exhibits periodicity of rods but not cells (Fig. 1b)

We add one scattered rod at half lattice constant at each corner, as shown in Fig. 1a (green color), in order to reduce the back reflection at the corresponding corner.
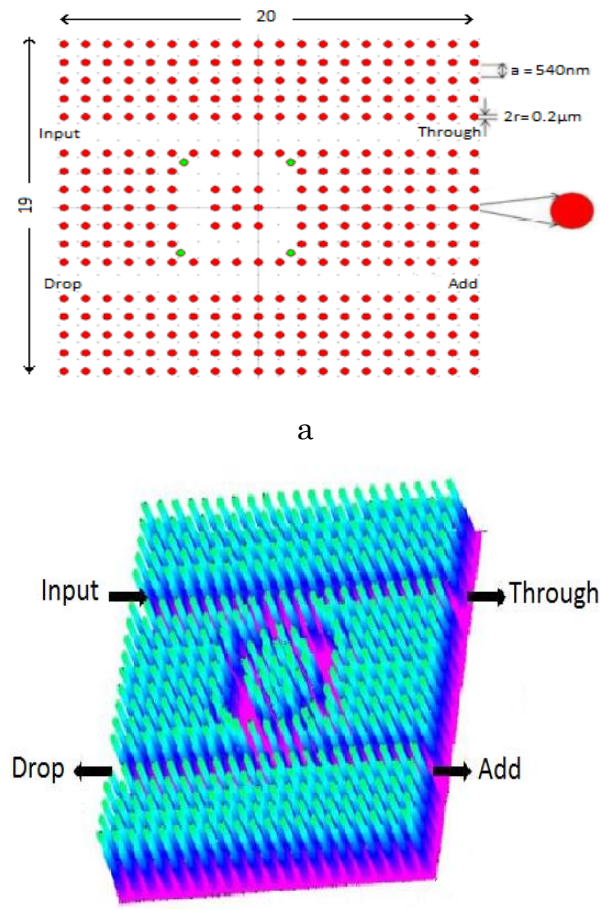

b

Fig. 1 - Structure of the ring photonic crystal (a), view of the 3D structure (b)

We used the band SOLVE to perform the plane wave expansion (PWE) calculation and to determine the band gap of the described structure. The dispersion curve was calculated and shown in Fig. 4.

The hatched areas (blue and red) reflect the photonic band gaps of two TE (transverse electric) and TM (transverse magnetic) polarizations, respectively.

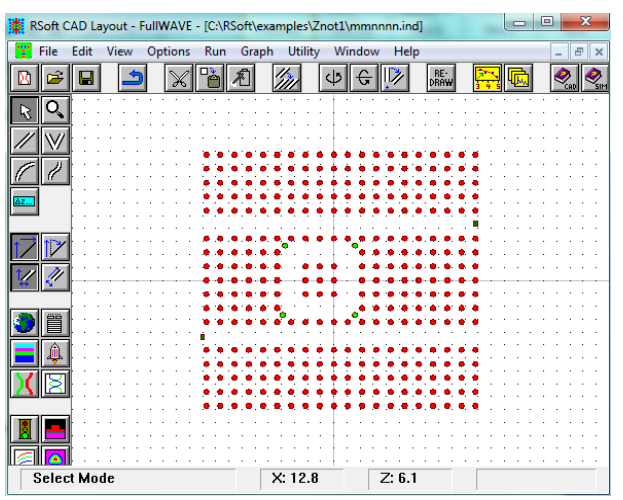

Fig. 2-Structure of the ring resonator based on photonic crystal in the software package

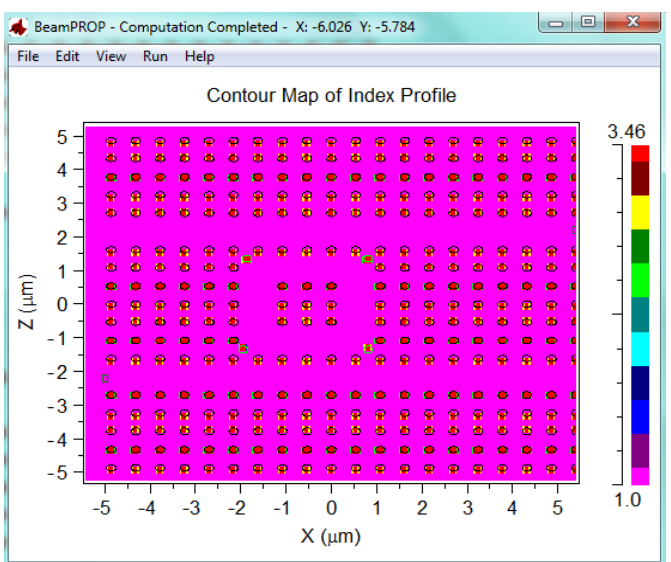

Fig. 3 - Profile index of the structure

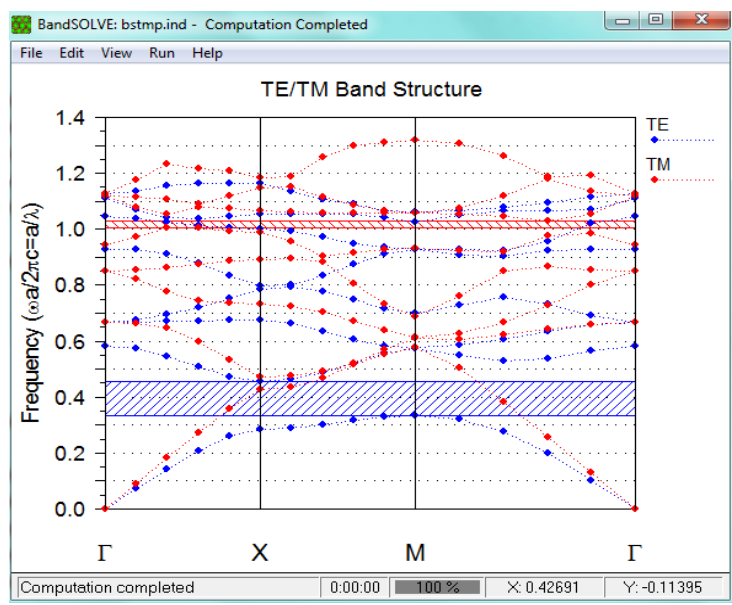

Fig. 4 - The band gaps for the PCRR

\section{SIMULATION AND RESULTS}

The photonic band gap ranges from $0.295 a / \lambda$ to $0.435 a / \lambda$ (where $a$ is the lattice constant equal to $540 \mathrm{~nm}$ ), which corresponds to $1241 \mathrm{~nm}$ to $1830 \mathrm{~nm}$ wavelength range. The propagation of a wave occurs according to the variation $\Gamma \rightarrow \mathrm{X} \rightarrow \mathrm{M} \rightarrow \Gamma$ of the vector wave in the Brillouin zone.

It should be noted here that this range fully covers the wavelength range where WDM is practiced in accordance with the standards of ITU (International Telecommunication Union). 
Examining the frequency response of the constructed model (Fig. 5), we consider the presence of a cavity mode at $\lambda=1.42 \mu \mathrm{m}$, i.e. there is a resonance at this wavelength.

As with a typical resonator, this resonance is manifested by extracting a wavelength from the input signal and sending it into the drop port. In other words, this is add-drop selective filtering, since other wavelengths can also be inserted via the add channel.

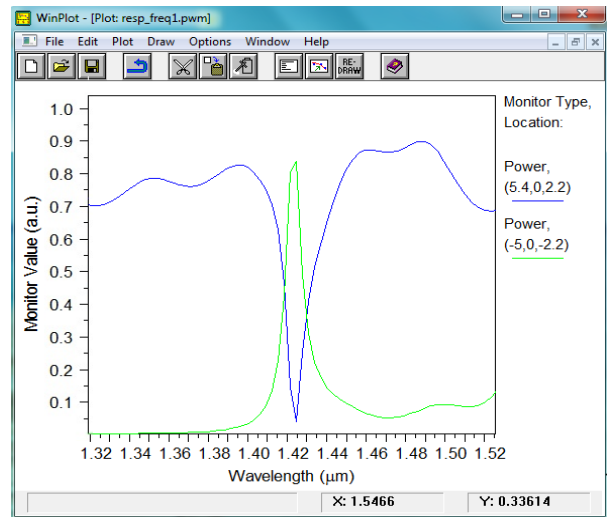

Fig. 5 - Spectral response of the structure
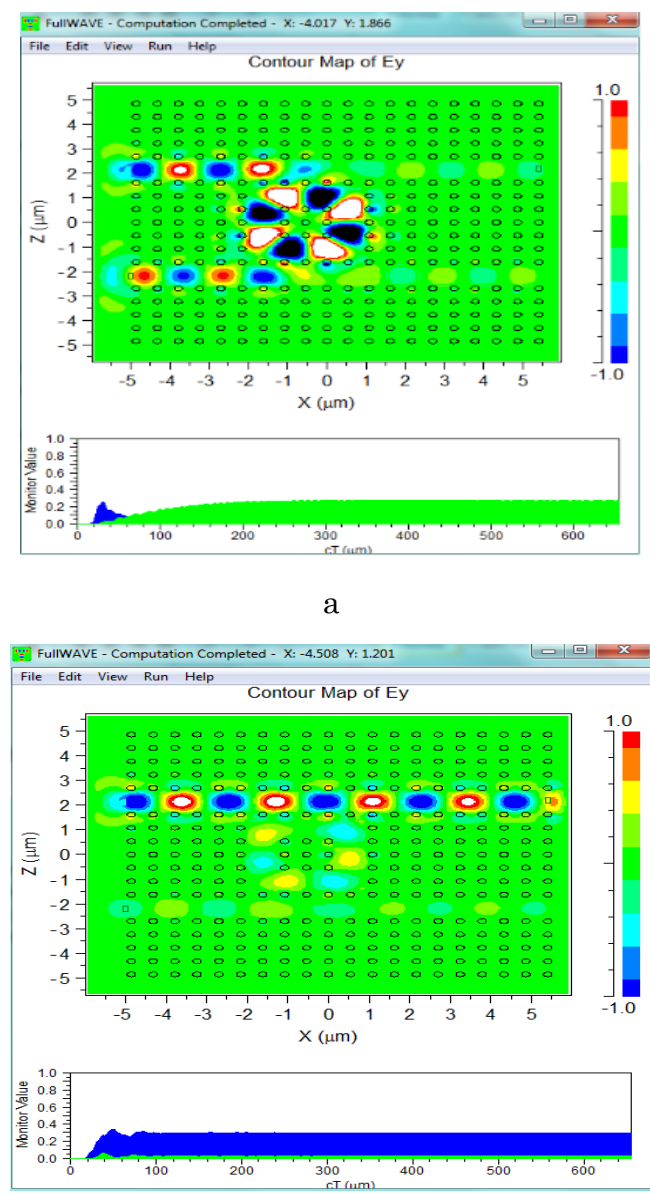

$\mathrm{b}$

Fig. 6 - CW simulation of the optical ring resonator based on photonic crystal at the resonance wavelength (a), off resonance (b)

We note, however, extraction efficiency (drop) close to $87 \%$, reflecting the device good selectivity.
Fig. 6 shows the result displaying the light distribution (electric field distribution) in the structure, in the central wavelength $(\mathrm{CW})$ mode, in the case of the resonance wavelength (a) and in the case of any outside resonance wavelength (b). Note that the estimated duration of the simulation is $45 \mathrm{~min}$.

In the case of resonance, light is coupled into the ring, leaves the resonance and is removed from the exit drop port (Fig. 6a). When the resonance conditions are not met, the incident light passes directly to the through port. In Fig. 6b, we clearly note the presence of some losses.

\section{TUNABILITY OF THE RESONANCE}

The tunability of the optical ring resonator to a specific wavelength requires very precise design and parameter selection, because the wavelength to be filtered must be that of the resonance, and the parameters must be redefined in order to be able to change it.

The most powerful way to tune the resonance wavelength is to alter the ring refractive index; this is an active tunability that can be accomplished by many effects such as the thermo-optical effect or electrooptical effect.

The choice of a ring material (including refractive index) is crucial, and its selection will depend on its intended application considering its direct effect on the resonance wavelength.

We carried out several simulations based on the importance of the dielectric permittivity and thus the refractive index of the ring rods, while keeping the other parameters unchanged. Each time, we reported the respective resonance wavelength and corresponding coupling efficiency. Table 1 summarizes the defined values.

Table 1 - Values of the resonance wavelength and coupling efficiency corresponding to different values of the dielectric constant of ring rods

\begin{tabular}{|c|c|c|}
\hline $\begin{array}{c}\text { Dielectric } \\
\text { constant }\end{array}$ & $\begin{array}{c}\text { Resonance } \\
\text { wavelength } \mathbf{( n m )}\end{array}$ & $\begin{array}{c}\text { Coupling } \\
\text { efficiency }\end{array}$ \\
\hline 7.84 & 1368 & 92 \\
\hline 9 & 1388 & 97 \\
\hline 10.24 & 1408 & 94 \\
\hline 11.56 & 1428 & 87 \\
\hline 12.96 & 1450 & 90 \\
\hline 14.44 & 1469 & 92 \\
\hline
\end{tabular}

As it can be noticed, the increase in the dielectric constant of the ring was responsible for the resonance wavelength shift, and the spacing between the resonant wavelengths was of the order of $20 \mathrm{~nm}$ (an allowed interval to practice the CWDM).

As for the coupling efficiency, it ranged between $87 \%$ and $97 \%$.

The dimensions of the proposed model also remained consistent with the integrated optics; so the total size of the device is $116 \mu \mathrm{m}^{2}$.

Furthermore, it can be seen that the filtered wavelength (resonance) has changed according to the refractive index (from $1.425 \mu \mathrm{m}$ to $1.388 \mu \mathrm{m}$ ). That said, the tunability of the optical ring resonator was possible without affecting its geometry, and the extraction efficiency we found here was very high (98\%). 


\section{CONCLUSIONS}

In this study, tunable $2 \mathrm{D}$ photonic crystal was developed and investigated using the FDTD process based on a ring resonator. This element is used to achieve a new type of ADF.

The system being studied practically relies on opti- cal coupling, because the wavelength to be filtered is that of resonance and its tunability is possible by the most efficient method, which is the change in the ring refractive index.

The simulations performed indicate that for the WDM network, this device can be a selective and tunable filter with an excellent efficiency extraction.

\title{
REFERENCES
}

1. R.D. Meade, A. Devenyi, J.D. Joannopoulos, O.L. Alerhand, D.A. Smith, K. Kash, J. Appl. Phys. 75, 4753 (1994).

2. A.R. Alija, L.J. Martinez, P.A. Postigo, C. Seassal, P. Viktorovitch, App. Phys. Lett. 89, 101102 (2006).

3. Foozieh Sohrabi, Tayebeh Mahinroosta, Seyedeh M. Hamidi, Opt. Eng. 53,115104 (2014).

4. Y. Zhuang, K. Ji, W. Zhou, H. Chen, IEEE Photon. Technol. Lett. 28, 1669 (2016)

5. A. Rostami, H. Alipour Banaei, F. Nazari, A. Bahrami, Optik 122, 1481 (2011).

6. V. Kannaiyan, R. Savarimuthu, S.K. Dhamodharan, Opt.Electron. Rev. 26, 108 (2018).

7. M.C. Parker, S.D. Walker, IEEE J. Select. Topic. Quantum Electron. 8 No 6, 1158 (2002).

8. F. Brik, N. Paraire, T. Boumaza, M. Bouchemat, Appl. Phys. B: Laser. Opt. 97, 841 (2009).

9. S. Robinson, Nakkeran, J. Optoelectron. Adv. Mater. 5, (2011).

10. H. Badaoui, M. Abri, Frequenz 68 No 11-12, 511 (2014).

11. R. Benjelloul, T. Bouchemat, M. Bouchemat, A. Benmerkhi, Nanosci. Nanotechnol. 6 No 1A, 13 (2016)

12. F. Bounaas, A. Labbani, Prog. Electromagn. Res. Lett. 90, 85 (2020).

13. A. Labbani, B. Tebboub, J. Nano- Electron. Phys. 12 No 1, $01002(2020)$.

14. S.H. Kim, H.Y. Ryu, G.H. Kim, Y.S. Choi, Y.H. Lee, J.S. Kim, Appl. Phys. Lett. 81 No 14, 2499 (2002).

15. M.Y. Mahmoud, G. Bassou, A. Taalbi, Z.M. Chekroun, Opt. Commun. 285 No 3, 368 (2012).

16. H. Alipour-Banaei, S. Serajmohammadi, F. Mehdizadeh, J. Optoelectron. Adv. Mater. 17 No 3-4, 259 (2015).

17. A. Taflove, S.C. Hegness, Computational Electrodynamics: The Finite Difference Time Domain Method, 2nd ed., (Artech House: Boston, MA, USA: 2000).

18. S.G. Johnson, J.D. Joannopoulos, Opt. Exp. 8 No 3, 173 (2001).

19. J.C. Chen, K. Li, Microwave Opt. Technol. Lett. 10, 319 (1995).

20. F. Brik, S. Harize, A. Fares, IEEE International Conference on Design \& Test of Integrated Micro \& Nano-systems, DTS (Tunisia, Apr. 28 - May 01, 2019).

\section{Оптимізація регульованого фільтра на фотонних кристалах для грубого мультиплексування з поділом по довжині хвилі}

\author{
F. Brik ${ }^{1}$, A. Labbani ${ }^{2}$ \\ ${ }^{1}$ Badji Mokhtar Annaba University, Laboratory of LERICA Communication \& Instrumentation, \\ Annaba, Algeria \\ 2 Mentouri Brother Constantine 1, Laboratory of Hyper Frequency and Semiconductors, Constantine, Algeria
}

$\mathrm{y}$ роботі запропоновано дизайн регульованого фільтра $\mathrm{ADF}$ на основі фротонного кристала, який вважаеться однією з найбільш перспективних технологій для мереж мультиплексування з поділом по довжині хвилі (WDM). Використовуючи інструмент Fullwave програми Rsoft CAD, ми зімітували модель кільцевого резонатора на фотонних кристалах, подібну до базової. Аналітичні методи Plane Wave Expansion (PWE) та 2D Finite Difference Time Domain (FDTD) використовувались для виконання моделювання та тестування оптичних властивостей системи. Результати моделювання дозволили реалізувати модель високоселективного регульованого кільцевого резонатора на фотонних кристалах із швидкістю вилучення приблизно 98 \% та площею близько 100 мкм² $^{2}$, яка сумісна із передбачуваною інтегрованою оптикою.

Ключові слова: ADF, Фотонний кристал, Регулювання, FDTD. 